\title{
An Association Between C-Reactive Protein Levels and the Occurrence of Cognitive Dysfunction After Heart Valve Replacement
}

Widya Istanto Nurcahyo (D) Anshoril Arifin'

Aria Dian Primatika'

Zainal Muttaqin (D) ${ }^{2}$

Cindy Elfira Boom ${ }^{3}$

M Sofyan Harahap'

Mochamat Mochamat'

Taufik Eko Nugroho (D)

Satrio Adi Wicaksono'

'Department of Anesthesiology and Intensive Care, Diponegoro University Faculty of Medicine/Dr. Kariadi General Hospital, Semarang City, Central Java Province, Indonesia; ${ }^{2}$ Department of Neurosurgery, Faculty of Medicine, Diponegoro University/Dr. Kariadi General Hospital, Semarang City, Central Java Province, Indonesia; ${ }^{3}$ Department of Anesthesiology and Intensive Care, Cardiovascular Centre, Harapan Kita Hospital, Jakarta, Indonesia
Correspondence: Widya Istanto Nurcahyo

Department of Anesthesiology and Intensive Care, Diponegoro University Faculty of Medicine/Dr. Kariadi General Hospital, Semarang City, Central Java Province, 50275, Indonesia

Fax +622476928010

Email widya_istanto2@yahoo.com; widya. istanto.dr@gmail.com
Background: Postoperative cognitive dysfunction (POCD) is defined as cognitive dysfunction related to inflammation after surgical procedures, which is common following cardiac surgery. Cognitive deficits are thought to result from a systemic inflammatory response. C-reactive protein (CRP) and other proinflammatory cytokines, which are released in response to inflammation, disrupt the blood-brain barrier and neurotransmission, resulting in POCD. This study aimed to determine the correlation between POCD and increased levels of CRP in patients who had undergone heart valve replacement.

Methods: This study comprised 32 patients with normal cognitive function undergoing heart valve replacement. The CRP levels were measured before surgery and on the second postoperative day, and cognitive function was examined via the Indonesian-adapted Montreal Cognitive Assessment (MOCA-INA) on the third postoperative day. Data were analyzed using Spearman correlation test.

Results: Of the 32 patients, 28 (87.5\%) experienced POCD. The median level of CRP was $6.6 \mathrm{mg} / \mathrm{dL}$ (interquartile range: 4.0, $8.3 \mathrm{~g} / \mathrm{dL}$ ). According to Spearman correlation test, increased levels of CRP were significantly related to POCD following heart valve replacement $(\mathrm{p}=0.003, \mathrm{r}=0.501)$. The receiver operating characteristic curve indicated that the CRP cutoff level was $3.345 \mathrm{mg} / \mathrm{dL}$, and the sensitivity and specificity were $89.3 \%$ and $75 \%$, respectively.

Conclusion: High expression level of CRP was correlated with POCD following heart valve replacement.

Keywords: C-reactive protein, cardiac surgical procedure, cognition disorders, cognitive dysfunction, heart valves, postoperative complication

\section{Introduction}

Postoperative cognitive dysfunction (POCD) is a cognitive dysfunction sequela, possibly related to inflammation after a surgical procedure. Compared to other surgical procedures, POCD is commonly found after cardiac surgery, especially valve replacement. ${ }^{1-3}$ Pathophysiology related to POCD after cardiac surgery has not been fully elucidated. It has been assumed that the cause of POCD after cardiac surgery is multifactorial, resulting from a variety of surgical procedures, patients and anesthetic variables. Risk factors for developing POCD include advanced age, low educational level, insulin resistance, and pre-existing heart or vascular disease. ${ }^{4-6}$ Additionally, it is hypothesized that POCD results from a longer inflammatory response following hypoperfusion during cardiac surgery, which affects the 
brain. $^{3,7-9}$ An extended period of hypoperfusion during cardiac surgery elicits systemic inflammatory responses that alter cerebral autoregulation, resulting in POCD. ${ }^{10,11}$ Several attempts have been made to alleviate POCD, including preoperative administration of dexamethasone, which resulted in significantly lower systemic inflammatory response incidence and lower $\mathrm{C}$-reactive protein that subsequently led to lower incidence of POCD. ${ }^{12}$ This finding indicates that inflammation is significantly associated with the development of POCD. Certain genotypes such as C-reactive protein (CRP) and P-selectin genotypes are correlated to higher inflammatory incidence and higher CRP levels. CRP serves as a non-specific biomarker during acute-phase response of inflammation, tissue damage, as well as infection and has been related to the development of POCD. ${ }^{13-15}$ Several studies demonstrated that increased CRP levels were associated with POCD. A study by Liu et $\mathrm{al}^{16}$ revealed that CRP and IL- 6 are significantly increased after heart surgery and elevated levels of CRP preoperatively are correlated to the development of POCD. These findings are also in accordance with a study by Hudetz et al, especially after coronary artery surgery using cardiopulmonary bypass. ${ }^{11}$ POCD remains an important issue, which is often understudied; however, it affects the quality of life in our population. In Indonesia, there is scarcity in the study of cognitive dysfunction after heart surgery procedure, and to our best knowledge, studies that evaluate the association between CRP levels and POCD after heart valve replacement are limited. This study aimed to investigate whether elevated CRP levels are associated with POCD following heart valve replacement.

\section{Materials and Methods}

\section{Patients}

In this cross-sectional study, all patients aged between 20 and 64 years underwent heart valve replacement between July and December 2020. Cognitive functions were evaluated using Indonesian version of Montreal Cognitive Assessment (MoCA-INA) which has been tested for validity and reliability. ${ }^{17,18}$ We favor the usage of MoCA-INA since it is superior to MMSE in detecting mild cognitive impairment. ${ }^{19,20}$ MoCA-INA has a total score of 30, consisted of multiple cognitive domains: memory, attention, executive function, language, visuospatial skill, calculation, concentration, abstraction and orientation. ${ }^{20} \mathrm{We}$ examined the cognitive function using MoCA-INA prior to surgery, with a score less than 26 determined as cognitive impairment. The exclusion criteria were a history of cognitive disturbance, a score of $<26$ on MoCA-INA, cerebrovascular accident up to 1 year before surgery, psychiatric disorder or neurodegenerative disease, hypertension, diabetes mellitus, obesity, and abnormal liver and renal functions in the study, as was refusal to participate. A total of 32 patients who provided informed consent and who did not fulfill the exclusion criteria were enrolled in the study.

\section{Variables}

Serum CRP levels were measured before valve replacement and at their expected peak concentration period, ie, $48 \mathrm{~h}$ after surgery. ${ }^{21,22}$ Analysis of CRP levels was performed using immunoturbidimetric technique on Cobas c501 autoanalyzer. POCD was defined as a temporary decline in cognitive function related to surgery. The MoCA-INA was administered preoperatively and on the third day after surgery to evaluate cognitive function. Disturbance in cognitive function was characterized by a MoCA-INA score of $<26$. The postoperative score was then used to categorize each patient into the POCD and non-POCD groups. Normal laboratory values are shown in Table 1.

\section{Anesthesia Protocol}

Standard protocol of anesthesia was used according to our institutional guidelines. A dose of $0.07 \mathrm{mg} / \mathrm{kg}$ midazolam

Table I Normal Laboratory Values

\begin{tabular}{|l|l|}
\hline Laboratory Values & Normal Value \\
\hline Hemoglobin, g/dL (median [IQR]) & $13.2-17.3$ \\
Hematocrit & $32-62 \%$ \\
Leukocyte count, $\times 10^{3} / \mu \mathrm{L}$ & $3.8-10.6$ \\
Platelet count, $\times 10^{3} / \mu \mathrm{L}$ & $150-400$ \\
Blood glucose level, $\mathrm{mg} / \mathrm{dL}$ & $80-160$ \\
Blood urea nitrogen level, $\mathrm{mg} / \mathrm{dL}$ & $15-39$ \\
Creatinine level, $\mathrm{mg} / \mathrm{dL}$ & $0.6-1.30$ \\
Albumin level, g/dL & $3.4-5.0$ \\
Aspartate aminotransaminase level, U/L & $15-34$ \\
Alanine aminotransaminase level, U/L & $15-60$ \\
Sodium level, mmol/L & $136-145$ \\
Potassium level, mmol/L & $3.5-5.0$ \\
Chloride, level mmol/L & $95-105$ \\
Calcium level, $\mathrm{mmol} / \mathrm{L}$ & $2.12-2.52$ \\
Magnesium level, mmol/L & $0.74-0.99$ \\
C-reactive protein level, $\mathrm{mg} / \mathrm{dL}$ & $0-0.30$ \\
\hline
\end{tabular}


was given as premedication. Anesthesia was induced via inhaled sevoflurane with Minimal Alveolar Concentration (MAC) of 1.0, continued by fentanyl $4 \mathrm{mcg} / \mathrm{kg}$ and rocuronium $1.2 \mathrm{mg} / \mathrm{kg}$ intravenous injection. It was maintained with 1.0 MAC inhaled sevoflurane, intravenous administration of $1 \mathrm{mcg} / \mathrm{kg}$ fentanyl per $30 \mathrm{~min}$ and $0.1 \mathrm{mg} / \mathrm{kg}$ rocuronium per $45 \mathrm{~min}$. The mean arterial pressure was set to $55-70 \mathrm{~mm} \mathrm{Hg}$ during cardiopulmonary bypass (CPB). Heparin (300 IU/kg) was administered to sustain an activated clotting time of $>400 \mathrm{~s}$. All patients received $0.02 \mathrm{mg} / \mathrm{kg}$ of morphine infusion for $48 \mathrm{~h}$ postoperatively.

\section{Data Analysis}

Statistical analysis was conducted using the Statistical Package for the Social Sciences 23.0 software (SPSS Inc.). The number of patients required in this study for statistical power was 32, and a total of 32 patients were enrolled. Data were calculated as medians (interquartile ranges [IQRs]) or percentages. To determine the correlation between increased levels of CRP and POCD, Spearman correlation test was employed. Data were considered significant if $P<0.05$.

\section{Ethical Statement}

All patients signed an informed consent before surgery. The procedures related to this study were reviewed and approved by the Health Research Ethics Committee of RSUP Dr. Kariadi Semarang in accordance with the declaration of Helsinki, with the number of ethical approval of No. 608/EC/KEPK-RSDK/2020.

\section{Results}

\section{Patient Characteristics and Preoperative Data}

A total of 32 patients were enrolled for valve replacement at our medical center. The patient characteristics are listed in Tables 2-4. POCD was later diagnosed following surgery. Of these patients, 28 (87.5\%) exhibited signs of POCD after a surgical procedure (MOCA-INA score of $<26$ ). The median age of all patients was 42.5 years (IQR: $35.2,52.0$ ), and most of the patients with POCD were older (median: 44.5; IQR: $37.5,54.2$ ) than those without (median: 29.5; IQR: 17.8, 40.5). With increased educational attainment, the proportion of participants who suffer from POCD decreases (elementary school $100 \%$, junior high school $90 \%$, senior high school $80 \%$ ). Of the participants, $50 \%$ had a history of atrial fibrillation, and POCD was later diagnosed in all those patients. POCD was common following mitral valve replacement with tricuspid valve repair (Table 3 ). In addition, preoperative CRP levels were higher in patients with POCD than in those without (Table 4).

\section{Intraoperative Data}

For the two groups of patients, the duration of surgery and anesthesia were different. In patients without POCD, the median duration of surgery was 130 min (IQR: 108, 145),

Table 2 Demographic and Preoperative Data

\begin{tabular}{|c|c|c|c|}
\hline Characteristics & All Patients & POCD & Non-POCD \\
\hline $\mathrm{n}$ & $32(100 \%)$ & $28(87.5 \%)$ & $4(12.5 \%)$ \\
\hline Age, years (median [IQR]) & $42.5(35.2,52.0)$ & $44.5(37.5,54.2)$ & $29.5(40.5,17.8)$ \\
\hline \multicolumn{4}{|l|}{ Sex } \\
\hline Female & $22(68.8 \%)$ & $19(54.2 \%)$ & $3(9.3 \%)$ \\
\hline Male & $10(31.2 \%)$ & $9(28.1 \%)$ & I (3.I\%) \\
\hline \multicolumn{4}{|l|}{ Education background } \\
\hline Elementary school & $7(21.9 \%)$ & $7(100 \%)$ & $0(0 \%)$ \\
\hline Junior high school & $10(31.3 \%)$ & $9(90 \%)$ & I (I0\%) \\
\hline Senior high school & I5 (46.9\%) & $12(80 \%)$ & $3(20 \%)$ \\
\hline Weight, kg (median [IQR]) & $51.0(46.0,63.8)$ & $51.5(45.2,66.2)$ & $50.5(48.5,57.8)$ \\
\hline Height, cm (median [IQR]) & $156.5(153.2,161.8)$ & $156.5(153.2,161.8)$ & $156.0(153.5,161.5)$ \\
\hline Body mass index, $\mathrm{kg} / \mathrm{m}^{2}$ (median [IQR]) & $21.05(19.35,24.31)$ & $21.40(19.33,24.55)$ & $20.66(19.52,23.46)$ \\
\hline History of atrial fibrillation & $16(50 \%)$ & $16(100 \%)$ & $0(0 \%)$ \\
\hline
\end{tabular}


Table 3 Preoperative Diagnosis and Surgical Procedure

\begin{tabular}{|c|c|c|c|}
\hline & All Patients & POCD & Non-POCD \\
\hline Mitral regurgitation & $27(100 \%)$ & $23(85.2 \%)$ & $4(14.8 \%)$ \\
\hline Mitral stenosis & $10(100 \%)$ & $9(90 \%)$ & $\mathrm{I}(10 \%)$ \\
\hline Aortic regurgitation & $12(100 \%)$ & $9(75 \%)$ & $3(25 \%)$ \\
\hline Aortic stenosis & $5(100 \%)$ & $5(100 \%)$ & $0(0 \%)$ \\
\hline Tricuspid regurgitation & $10(100 \%)$ & $8(80 \%)$ & $2(20 \%)$ \\
\hline Pulmonary regurgitation, mild & $4(12.5 \%)$ & $4(100 \%)$ & $0(0 \%)$ \\
\hline Pulmonary hypertension & I (3.1\%) & I (100\%) & $0(0 \%)$ \\
\hline \multicolumn{4}{|l|}{ Surgical procedure } \\
\hline MVR & II (34.4\%) & $10(90.9 \%)$ & I (9.1\%) \\
\hline Aortic valve replacement & $3(9.4 \%)$ & $2(66.7 \%)$ & I (33.3\%) \\
\hline DVR & $5(15.6 \%)$ & $5(100 \%)$ & $0(0 \%)$ \\
\hline MVR + TV repair & II (34.4\%) & 10 (90.9\%) & I (9.1\%) \\
\hline DVR + TV repair & $2(6.3 \%)$ & I (50\%) & I (50\%) \\
\hline Echocardiography: LVEF (median [IQR]) & $64.1 \%(51.1 \%, 67.7 \%)$ & $64.1 \%(51.1 \%, 67.7 \%)$ & $64.2 \%(51.5 \%, 71.1 \%)$ \\
\hline
\end{tabular}

Abbreviations: DVR, double valve replacement; MVR, mitral valve replacement; POCD, postoperative cognitive dysfunction; TV, tricuspid valve.

Table 4 Pre and Postoperative Data in POCD

\begin{tabular}{|c|c|c|c|}
\hline & Preoperative & Postoperative & Differences \\
\hline Hemoglobin, g/dL (median [IQR]) & $12.85(13.95,12.05)$ & $10.95(10.40,11.85)$ & $-1.9(-14.79 \%)$ \\
\hline Hematocrit & $38.95 \%(34.75 \%, 4 I .50 \%)$ & $32.50 \%(31.55 \%, 35.15 \%)$ & $-6.45(-16.56 \%)$ \\
\hline Leukocyte count, $\times 10^{3} / \mu \mathrm{L}$ & $7.80(5.72,9.05)$ & $12.6(10.9,14.5)$ & $4.80(61.54 \%)$ \\
\hline Platelet count, $\times 10^{3} / \mu \mathrm{L}$ & $257.5(232.5,286.8)$ & $162(138,181.5)$ & $-95.5(-37.09 \%)$ \\
\hline Blood glucose level, mg/dL & $94.0(81.2,108.5)$ & $172(150.2,197.5)$ & 78 (82.98\%) \\
\hline Blood urea nitrogen level, $\mathrm{mg} / \mathrm{dL}$ & $31.5(26.2,39.2)$ & $31.0(26.5,34.8)$ & $-0.50(-1.59 \%)$ \\
\hline Creatinine level, $\mathrm{mg} / \mathrm{dL}$ & $1.01(0.83,1.15)$ & $1.0(0.9,1.1)$ & $-0.01(-0.99 \%)$ \\
\hline Albumin level, g/dL & $4.3(4.0,4.5)$ & $3.6(3.15,4.13)$ & $-0.70(-16.28 \%)$ \\
\hline Aspartate aminotransaminase level, U/L & $25(22,27)$ & $36.0(28.0,43.8)$ & II.0 (44\%) \\
\hline Alanine aminotransaminase level, $\mathrm{U} / \mathrm{L}$ & $22(14,25)$ & $21.5(18.0,28.8)$ & $-0.50(-2.27 \%)$ \\
\hline Sodium level, $\mathrm{mmol} / \mathrm{L}$ & $138.5(134.2,142.8)$ & $138(135,140)$ & $-0.50(-0.36 \%)$ \\
\hline Potassium level, mmol/L & $3.9(3.6,4.2)$ & $4.2(3.8,5.1)$ & $0.30(7.69 \%)$ \\
\hline Chloride, level mmol/L & $101(99,104)$ & I0I $(98.2,105.8)$ & $0(0 \%)$ \\
\hline Calcium level, $\mathrm{mmol} / \mathrm{L}$ & $2.28(2.18,2.40)$ & $2.10(2.02,2.24)$ & $-0.18(-7.89 \%)$ \\
\hline Magnesium level, mmol/L & $0.87(0.79,0.95)$ & $0.8(0.7,0.9)$ & $-0.07(-8.05 \%)$ \\
\hline C-reactive protein level, $\mathrm{mg} / \mathrm{dL}$ & $0.16(0.12,0.21)$ & $7.18(4.71,8.83)$ & $7.02(4387.5 \%)$ \\
\hline MoCA-INA score & $27.5(27.0,29.0)$ & $17.5(14.0,21.75)$ & $10(-36.36 \%)$ \\
\hline
\end{tabular}

and the duration of anesthesia was $292.5 \mathrm{~min}$ (IQR; Table 5). Contrarily, in patients with POCD, both durations were shorter. The durations of cardiopulmonary bypass time (CPB) and cross-clamping were also shorter in patients with POCD. During surgery, direct current shocks were administered to almost all patients but more commonly to those who later developed POCD; ventricular fibrillation was the most common reason.

\section{Postoperative Data}

Postoperative leukocyte and CRP levels were higher in patients with POCD than in those without (Table 4).

\section{Bivariable Analysis}

To determine the correlation between increased levels of CRP and POCD, we used Spearman correlation test. Increased CRP levels were significantly correlated with 
Table 5 Intraoperative Data

\begin{tabular}{|c|c|c|c|}
\hline Characteristics & All Patients & POCD & Non-POCD \\
\hline $\mathrm{n}$ & $32(100 \%)$ & $28(87.5 \%)$ & $4(12.5 \%)$ \\
\hline Surgery duration, minutes (median [IQR]) & $120(95,134)$ & $120(95,134)$ & $130(108,145)$ \\
\hline Anesthesia duration, minutes (median [IQR]) & $260(218,289)$ & $245(202,280)$ & $292.5(273.8,300.0)$ \\
\hline CPB duration, minutes (median [IQR]) & $40.5(34.2,56.8)$ & $40.5(34.2,54.8)$ & $47.0(35.0,70.2)$ \\
\hline Cross-clamp duration, minutes (median [IQR]) & $23(20,47)$ & $23(20,46)$ & $30.5(20.0,50.8)$ \\
\hline \multicolumn{4}{|l|}{ Patients given direct current shocks } \\
\hline One shock & $17(53.1 \%)$ & 7 (87.5\%) & I (25\%) \\
\hline Two shocks & $17(53.1 \%)$ & $15(88.2 \%)$ & $2(11.8 \%)$ \\
\hline Three shocks & $2(6.3 \%)$ & $2(100 \%)$ & $0(0 \%)$ \\
\hline Four or more shocks & $2(6.3 \%)$ & $2(100 \%)$ & $0(0 \%)$ \\
\hline \multicolumn{4}{|l|}{ Indication for direct current shock } \\
\hline Ventricular fibrillation & $24(75 \%)$ & $22(91.7 \%)$ & $2(8.3 \%)$ \\
\hline Ventricular tachycardia & $2(6.3 \%)$ & $2(100 \%)$ & $0(0 \%)$ \\
\hline Atrial fibrillation & $2(6.3 \%)$ & I (50\%) & I (50\%) \\
\hline Bleeding volume, $\mathrm{mL}$ (median [IQR]) & $350(300,365)$ & $350(300,378)$ & $300(300,338)$ \\
\hline Temperature during $\mathrm{CPB},{ }^{\circ} \mathrm{C}$ (median $[\mathrm{IQR}]$ ) & $32.5(31.5,33.8)$ & $32.2(31.5,33.5)$ & $33.5(31.9,34.6)$ \\
\hline Temperature during rewarming after $\mathrm{CPB},{ }^{\circ} \mathrm{C}$ (median $[\mathrm{IQR}]$ ) & $31.75(31.5,32.2)$ & $31.75(31.42,32.2)$ & $31.85(31.55,34.32)$ \\
\hline Nasopharynx temperature during rewarming after $\mathrm{CPB},{ }^{\circ} \mathrm{C}$ (median $[\mathrm{IQR}]$ ) & $32.95(31.52,34.08)$ & $32.95(31.6,34.0)$ & $33.0(31.25,35.05)$ \\
\hline Temperature when $\mathrm{CPB}$ was discontinued, ${ }^{\circ} \mathrm{C}$ (median [IQR]) & $36.1(36.0,36.2)$ & $36.1(36.1,36.3)$ & $36.05(35.4,36.18)$ \\
\hline
\end{tabular}

Abbreviations: $C P B$, cardiopulmonary bypass; POCD, postoperative cognitive dysfunction.

POCD after valve replacement $(\mathrm{r}=0.501, P<0.01)$. The overall median level of increased CRP was $6.6 \mathrm{mg} / \mathrm{dL}$ (IQR: 4.0, 8.3); the median CRP level in the POCD group was higher in patients with POCD (median: 7.05; IQR: $4.52,8.46$ ) than in those without (median: 2.98; IQR: 2.28, 3.83; Table 6).

\section{Receiver Operating Characteristic Curve Analysis}

The area under the receiver operating characteristic curve was 0.938, indicating that increased CRP level was an excellent tool for predicting POCD. The receiver operating characteristic curve analysis demonstrated that a CRP concentration cutoff of $3.345 \mathrm{mg} / \mathrm{dL}$ had an optimum balance between sensitivity $(89.3 \%)$ and specificity (75\%) for POCD (Figure 1).

\section{Discussion}

In investigating the role of CRP in patients with POCD, we found that the majority $(87.5 \%)$ of patients exhibited POCD following heart valve replacement, according to the MoCAINA scores of $<26$. These results were in agreement with those in other studies, in which POCD was found in $33.0 \%{ }^{6}$ and $44.5 \%{ }^{23}$ of the participants after cardiac surgery. The differences in the proportions might be attributable to the use of different assessment methods for cognitive evaluation and to the time of postoperative examination.

The risk factors that contributed to POCD were divided into preoperative, intraoperative, and postoperative. A recent narrative review conducted by Glumac et al identified various preoperative risk variables, including age, gender, educational background, obesity, and a history of metabolic

Table 6 Bivariate Analysis

\begin{tabular}{|l|c|c|c|c|c|}
\hline Characteristics & All Patients & POCD & Non-POCD & P value & R value \\
\hline $\mathrm{n}$ & $32(100 \%)$ & $28(87.5 \%)$ & $4(12.5 \%)$ & & \\
Elevated levels of C-reactive protein, $\mathrm{mg} / \mathrm{dL}($ median $[\mathrm{IQR}])$ & $6.6(4.0,8.3)$ & $7.05(4.52,8.46)$ & $2.98(2.28,3.83)$ & $0.003^{*}$ & $0.50 \mathrm{I}$ \\
\hline
\end{tabular}

Abbreviation: POCD, postoperative cognitive dysfunction. 


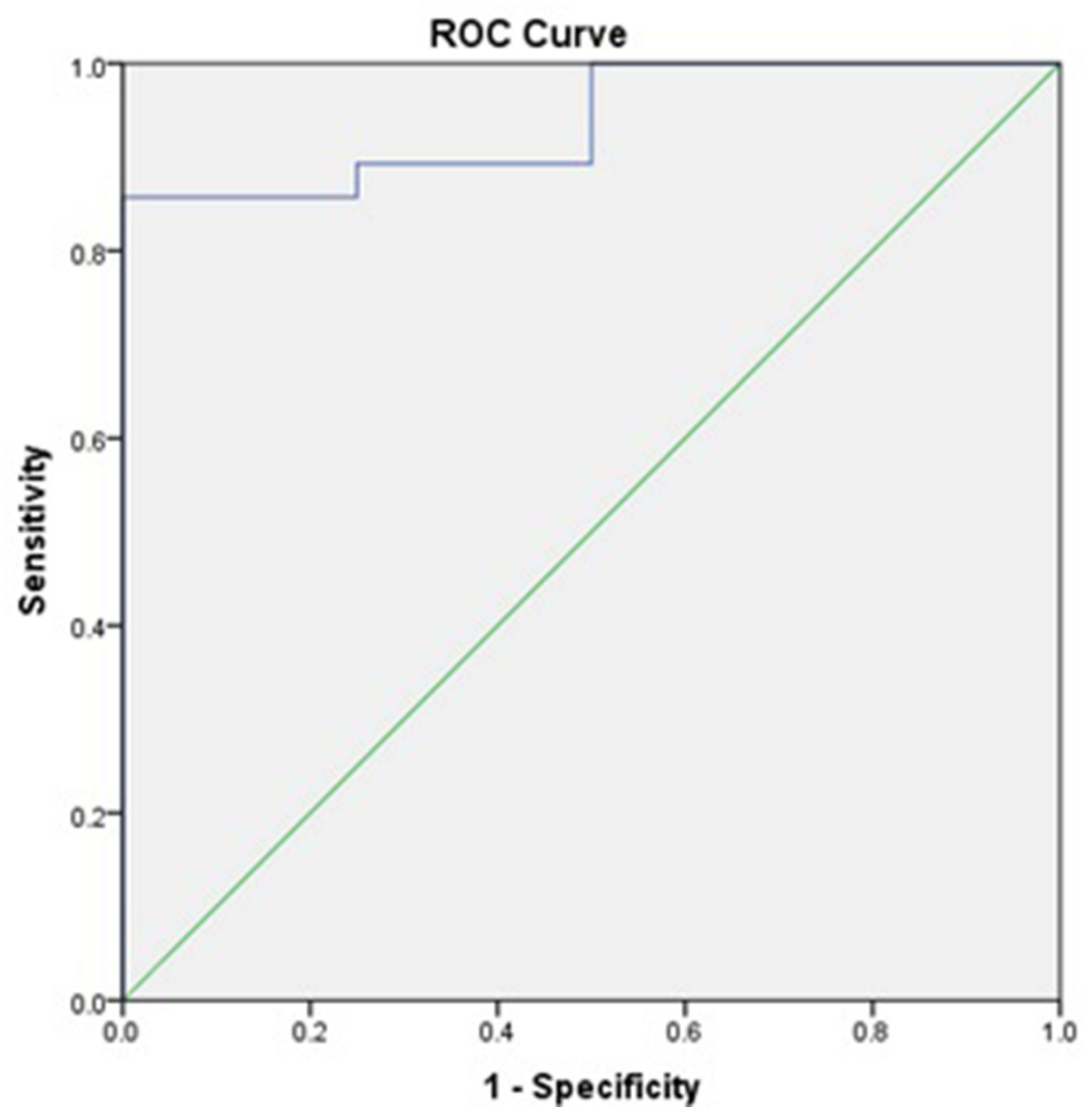

Figure I Receiver operating characteristic (ROC) curve analysis of CRP level as diagnostic tool of POCD. CRP concentration cutoff of $3.345 \mathrm{mg} / \mathrm{dL}$ was selected with $89.3 \%$ sensitivity and $75 \%$ specificity. Area under the curve (AUC) was 0.938 .

syndrome. ${ }^{24}$ Previous studies demonstrated that the risk of POCD was significantly increased in older patients who had undergone previous surgery, either cardiac or noncardiac. ${ }^{25}$ In our study, the patients with POCD (median age: 44.5 years; IQR: 37.5, 54.2) were older than those without (median: 29.5 years; IQR: 17.8, 40.5). Aging might be associated with degenerative changes in the brain and thereby increase the risk of POCD over the long-term following surgery. Additionally, our study discovers that the proportion of people suffering from POCD reduces with increasing educational attainment (elementary school 100\%, junior high school $90 \%$, senior high school $80 \%$ ). This finding is consistent with a study conducted by Feinkohl et al, which discovered that patients who spent more time in school had a lower risk of developing POCD. ${ }^{26}$

Hypoxemia, hypotension, thrombus, and emboli were intraoperative risk factors for POCD. ${ }^{27}$ Longer operation time and complex surgical strategy are related to endotoxin release and increase the risk of brain emboli, which could increase the risk of POCD. The duration and depth of anesthesia are also related to cerebral oxygenation, the decrease of which could further contribute to the development of POCD. Previous studies demonstrated longer duration of surgery in patients who developed POCD. Sun et $\mathrm{al}^{28}$ suggested that the correlation between longer surgery duration and POCD incidence was significant. However, some studies did not prove the significance of this correlation and contrary to previous studies, our patients with POCD had shorter periods of surgery and anesthesia than did patients without POCD. ${ }^{29,30}$ The median durations of surgery and anesthesia for all patients were $120 \mathrm{~min}$ (IQR: 95, 134) and 260 min (IQR: 218, 289), respectively. A potential explanation for this result might be the limited sample size in comparison with prior studies. 
Cognitive function deficits are related to CBP duration, cross-clamping duration, and the rewarming process in cardiac surgery. ${ }^{6,24,31}$ The inflammatory response to CBP includes the production of proinflammatory cytokines. As the inflammatory response progresses, normal blood-brain barrier and neurotransmission functions are disrupted, resulting in edema and cerebral inflammation. Edema and brain inflammation play a role in the pathogenesis of POCD. ${ }^{32}$ In addition because the circulation during crossclamping is completely artificial, cerebral hypoperfusion could result, which would support the development of POCD. Our study demonstrated that the duration of CPB and cross-clamping was shorter in patients with POCD. However, our study was limited by the sample size.

We analyzed the association of increased CRP concentration with the incidence of POCD. As mentioned, POCD was defined by a MoCA-INA score of $<26$ on the third day following surgery. The CRP levels were measured preoperatively and 2 days after surgery. Spearman correlation test revealed a significant correlation between CRP with POCD after valve replacement $(p=0.003)$. Our findings are consistent with those of Liu et $\mathrm{al}^{16}$ and Hudetz et $\mathrm{al}^{11}$ both of whom found that the CRP levels increased after cardiac surgery and that these increases were related to POCD. Although the standard of POCD diagnosis is based on comprehensive psychometric batteries, the use of such batteries in our clinical settings is limited due to the lack of trained neuropsychologists to perform such detailed assessment. Therefore, we used MoCA INA, which is adapted from the MoCA specifically for the Indonesian population, which required less time and resources to perform. MoCA is more suitable for screening postoperative MCI compared with MMSE. ${ }^{19}$ Studies in patients who underwent noncardiac surgery also demonstrated that increasing the CRP levels $24 \mathrm{~h}$ after surgery were significantly correlated with POCD; in patients with POCD, the CRP levels were 1.7 times higher than the preoperative CRP levels. ${ }^{33}$ This result indicated that the CRP level is a good biomarker for POCD-related inflammation.

To prevent the development of POCD, pharmacological strategies such as the use of anti-inflammatory drugs, dexmedetomidine, and statins have been proposed. $^{34}$ Nonsteroidal anti-inflammatory drugs and paracetamol were administered to reduce the concentrations of proinflammatory cytokines (interleukin-1 $\beta$, tumor necrosis factor $\alpha$, interleukin- 6 , and prostaglandins) in the hippocampus, with the aim of improving cognitive function. The administration of glucocorticoid drugs such as dexamethasone also helped lower the CRP levels. ${ }^{12,35}$ Reductions in CRP levels may lower the incidence of POCD.

In the receiver operating characteristic curve analysis for diagnostic assessment of increasing CRP levels, we found that the area under the curve was 0.938 , and the cutoff CRP level of $3.345 \mathrm{mg} / \mathrm{dL}$ had $89.3 \%$ sensitivity and $75 \%$ specificity. These findings indicated that an increase in the CRP level after surgery was a good prognostic factor for determining the risk of POCD.

This study has several limitations. We did not perform a neuropsychological test battery and evaluate the long-term relationship between CRP and cognitive function. We suggest that further studies should incorporate larger sample sizes, the use of battery neuropsychological test in determining POCD status, and long-term follow-up after surgery.

\section{Conclusion}

POCD is a complication of heart valve surgery that must not be ignored by clinicians. Evidence suggests that the inflammatory response plays a significant role in cognitive decline following surgery. An increased level of CRP is useful as a good predictor of POCD after heart valve replacement. However, the complicated pathogenesis and complex risk factors involved in POCD must be further studied, as should long-term cognitive outcomes.

\section{Disclosure}

The authors report no conflicts of interest in this work.

\section{References}

1. Oldham MA, Vachon J, Yuh D, Lee HB. Cognitive outcomes after heart valve surgery: a systematic review and Meta-analysis. $J \mathrm{Am}$ Geriatr Soc. 2018;66(12):2327-2334. doi:10.1111/jgs.15601

2. Pappa M, Theodosiadis N, Andreas Tsounis PS. Pathogenesis and treatment of post-operative cognitive dysfunction Maria. Electron Physician. 2017;9(2):3592-3597. doi:10.19082/3768

3. Hovens IB, van Leeuwen BL, Mariani MA, Kraneveld AD, Schoemaker RG. Postoperative cognitive dysfunction and neuroinflammation; Cardiac surgery and abdominal surgery are not the same. Brain Behav Immun. 2016;54:178-193. doi:10.1016/j.bbi.20 16.02.003

4. Czyż-Szypenbej1 K, Mędrzycka-Dąbrowska W, Kwiecień-Jaguś K, Lewandowska K. The occurrence of postoperative cognitive dysfunction (POCD) - systematic review. Psychiatr Pol. 2019;53(1):145-160. doi:10.12740/PP/90648

5. Mędrzycka-Dąbrowska W, Dąbrowski S, Basiński A. Assessment of selected cognitive processes in elderly patients after urologic surgery. Neurol Neurochir Pol. 2016;50(3):163-171. doi:10.1016/j.pjnns.20 16.02.004

6. Xu T, Bo L, Wang J, et al. Risk factors for early postoperative cognitive dysfunction after non-coronary bypass surgery in Chinese population. J Cardiothorac Surg. 2013;8(1):1. doi:10.1186/1749-8090-8-204 
7. Knipp SC, Weimar C, Schlamann M, et al. Early and long-term cognitive outcome after conventional cardiac valve surgery. Interact Cardiovasc Thorac Surg. 2017;24(4):534-540. doi:10.1093/icvts/ivw421

8. Zimpfer D, Czerny M, Kilo J, et al. Cognitive deficit after aortic valve replacement. Ann Thorac Surg. 2002;74(2):407-412. doi:10.1016/S0003-4975(02)03651-2

9. Öztürk S, Saçar M, Baltalarlı A, Öztürk İ. Effect of the type of cardiopulmonary bypass pump flow on postoperative cognitive function in patients undergoing isolated coronary artery surgery. Anatol J Cardiol. 2016;16(11):875-880. doi:10.14744/AnatolJCardiol.2015.6572

10. Scott DA, Evered LA, Silbert BS. Cardiac surgery, the brain, and inflammation. J Extra Corpor Technol. 2014;46(1):15-22.

11. Hudetz JA, Gandhi SD, Iqbal Z, Patterson KM, Pagel PS. Elevated postoperative inflammatory biomarkers are associated with short- and medium-term cognitive dysfunction after coronary artery surgery. J Anesth. 2011;25(1):1-9. doi:10.1007/s00540010-1042-y

12. Glumac S, Kardum G, Sodic L, Supe-Domic D, Karanovic N. Effects of dexamethasone on early cognitive decline after cardiac surgery; A randomised controlled trial. Eur J Anaesthesiol. 2017;34 (11):776-784. doi:10.1097/EJA.0000000000000647

13. Tan AMY, Amoako D. Postoperative cognitive dysfunction after cardiac surgery. Contin Educ Anaest Crit Care Pain. 2013;13 (6):218-223. doi:10.1093/bjaceaccp/mkt022

14. Androsova G, Krause R, Winterer G, Schneider R. Biomarkers of postoperative delirium and cognitive dysfunction. Front Aging Neurosci. 2015;7:(JUN):1-16. doi:10.3389/fnagi.2015.00112

15. Peng L, Xu L, Ouyang W. Role of peripheral inflammatory markers in Postoperative Cognitive Dysfunction (POCD): a meta-analysis. PLoS One. 2013;8(11):1-10. doi:10.1371/journal.pone.0079624

16. Liu X, Yu Y, Zhu S. Erratum: inflammatory markers in postoperative delirium (POD) and cognitive dysfunction (POCD): a meta-analysis of observational studies. PLoS One. 2018;13(12):1-22. doi:10.1371/ journal.pone.0209284

17. Husein N, Lumempouw S, Ramli Y. Uji validitas dan reliabilitas Montreal Cognitive Assesment versi Indonesia (MoCA-Ina) untuk skrining gangguan fungsi kognitif [Validity and realibility study of Montreal Cognitive Assessment Indonesia version (MoCA-Ina) for screening cognitive function disorder]. Neurona. 2010;27(4):15-22. Indonesian.

18. Akbar NL, Effendy E, Camellia V. The Indonesian Version of Montreal Cognitive Assessment (MoCA-Ina): the difference scores between Male Schizophrenia prescribed by Risperidone and Adjunctive of Donepezil in public hospital of Dr Pirngadi Medan, Indonesia. Open Access Maced J Med Sci. 2019;7(11):1762-1767. doi:10.3889/oamjms.2019.461

19. Dong Y, Sharma VK, Chan BPL, et al. The Montreal Cognitive Assessment (MoCA) is superior to the Mini-Mental State Examination (MMSE) for the detection of vascular cognitive impairment after acute stroke. J Neurol Sci. 2010;299(1-2):15-18. doi:10.1016/j.jns.2010.08.051

20. Vide S, Gambús PL. Tools to screen and measure cognitive impairment after surgery and anesthesia. Press Medicale. 2018;47(4P2): e65-e72. doi:10.1016/j.lpm.2018.03.010

Vascular Health and Risk Management

\section{Publish your work in this journal}

Vascular Health and Risk Management is an international, peerreviewed journal of therapeutics and risk management, focusing on concise rapid reporting of clinical studies on the processes involved in the maintenance of vascular health; the monitoring, prevention and treatment of vascular disease and its sequelae; and the involvement
21. World Health Organization. C-reactive protein concentrations as a marker of inflammation or infection for interpreting biomarkers of micronutrient status. Vitam Miner Nutr Inf Syst. 2014:1-4. Available from: http://apps.who.int/iris/bitstream/10665/133708/1/WHO_ $\mathrm{NMH}$ _NHD_EPG_14.7_eng.pdf?ua $=1$.

22. Neumaier M, Metak G, Scherer MA. C-reactive protein as a parameter of surgical trauma: CRP response after different types of surgery in 349 hip fractures. Acta Orthop. 2006;77(5):788-790. doi:10.1080/17453670610013006

23. Ziyaeifard M, Alizadehasl A, Amiri M, et al. Prevalence and predisposing factors for cognitive dysfunction following adult cardiac surgery. Res Cardiovasc Med. 2017;6(2):5. doi:10.5812/cardiovascmed.37284

24. Glumac S, Kardum G, Karanovic N. Postoperative cognitive decline after cardiac surgery: a narrative review of current knowledge in 2019. Med Sci Monit. 2019;25:3262-3270. doi:10.12659/MSM.914435

25. Rundshagen I. Postoperative cognitive dysfunction. Dtsch Arztebl Int. 2014;111(8):119-125. doi:10.3238/arztebl.2014.0119

26. Feinkohl I, Winterer G, Spies CD, Pischon T. Cognitive reserve and the risk of postoperative cognitive dysfunction - A systematic review and meta-analysis. Dtsch Arztebl Int. 2017;114(7):110-117. doi:10.3238/arztebl.2017.0110

27. Wang W, Wang Y, Wu H, et al. Postoperative cognitive dysfunction: current developments in mechanism and prevention. Med Sci Monit. 2014;20:1908-1912. doi:10.12659/MSM.892485

28. Sun Y, Feng H, Zou T, et al. Assessment of risk factors for postoperative cognitive dysfunction after coronary artery bypass surgery: a single-center retrospective cohort study. Biosci Rep. 2021;41(2): BSR20190719. doi:10.1042/BSR20190719

29. Zhang Y, Bao HG, Lv YL, et al. Risk factors for early postoperative cognitive dysfunction after colorectal surgery. BMC Anesthesiol. 2019;19(1):1-6. doi:10.1186/s12871-018-0676-4

30. Oliveira FR, Oliveira VH, Oliveira ÍM, et al. Hypertension, mitral valve disease, atrial fibrillation and low education level predict delirium and worst outcome after cardiac surgery in older adults. $B M C$ Anesthesiol. 2018;18(1):1-8. doi:10.1186/s12871-018-0481-0

31. Patel N, Minhas JS, Chung EML. Risk factors associated with cognitive decline after cardiac surgery: a systematic review. Cardiovasc Psychiatry Neurol. 2015;2015:1-12. doi:10.1155/2015/370612

32. Van Harten AE, Scheeren TWL, Absalom AR. A review of postoperative cognitive dysfunction and neuroinflammation associated with cardiac surgery and anaesthesia. Anaesthesia. 2012;67 (3):280-293. doi:10.1111/j.1365-2044.2011.07008.x

33. Li X, Wen DX, Zhao YH, Hang YN, Mandell MS. Increase of beta-amyloid and C-reactive protein in liver transplant recipients with postoperative cognitive dysfunction. Hepatobiliary Pancreat Dis Int. 2013;12(4):370-376. doi:10.1016/S1499-3872(13)60058-2

34. Safavynia SA, Goldstein PA. The role of neuroinflammation in postoperative cognitive dysfunction: moving from hypothesis to treatment. Front Psychiatry. 2019;9:752. doi:10.3389/fpsyt.2018.00752.

35. Toner AJ, Ganeshanathan V, Chan MT, Ho KM, Corcoran TB. Safety of perioperative glucocorticoids in elective noncardiac surgery. Anesthesiology. 2017;126(2):234-248. doi:10.1016/S0003-4975(10) 61332-X

of metabolic disorders, particularly diabetes. This journal is indexed on PubMed Central and MedLine. The manuscript management system is completely online and includes a very quick and fair peerreview system, which is all easy to use. Visit http://www.dovepress. com/testimonials.php to read real quotes from published authors. 